\title{
Perigraft air and endoleak post endovascular repair of abdominal aortic aneurysm: is it always catastrophic?
}

\author{
Amit Ajit Deshpande 지 , Amarinder Singh Malhi, Debanjan Nandi, Sanjeev Kumar
}

Cardiovascular Radiology and Endovascular Interventions, All India Institute of Medical Sciences, New Delhi, India

\section{Correspondence to Dr Sanjeev Kumar;} sanjeevradio@gmail.com

Accepted 30 May 2021

\section{DESCRIPTION}

A 68-year-old man with hypertension presented with a sudden onset of abdominal pain radiating to the back. An abdominal ultrasound revealed a large peripherally thrombosed pseudoaneurysm of the infra-abdominal aorta. A CT angiogram confirmed the abdominal aortic aneurysm (AAA) with a maximum diameter of $5.8 \mathrm{~cm}$ and contained rupture as evidenced by the periaortic haematoma (figure 1A). The aneurysm was extending up to the aortic bifurcation with an incidental finding of right renal artery stenosis. Bilateral common iliac arteries showed atherosclerotic changes without any significant stenosis or tortuosity (figure 2A).

The patient was taken up for endovascular repair (EVAR) of the AAA owing to the lesion morphology. The abdominal aortic stent-graft (Endurant II, Medtronic, USA) was deployed via the left femoral access with the suprarenal fixation of the proximal end and distal end in the ipsilateral common iliac artery (CIA). The iliac limb extension of the stentgraft (Medtronic, USA) was deployed from the right common femoral artery (CFA) access with its distal end in the ipsilateral CIA. The check angiogram revealed good proximal and distal approximation of the stent-graft. However, a jet of contrast is seen extending into the perigraft aorta from the carina of the stent-graft (figure 2 and video 1), which was reduced after an interval angiogram postnormalisation of the activated clotting time. It suggests

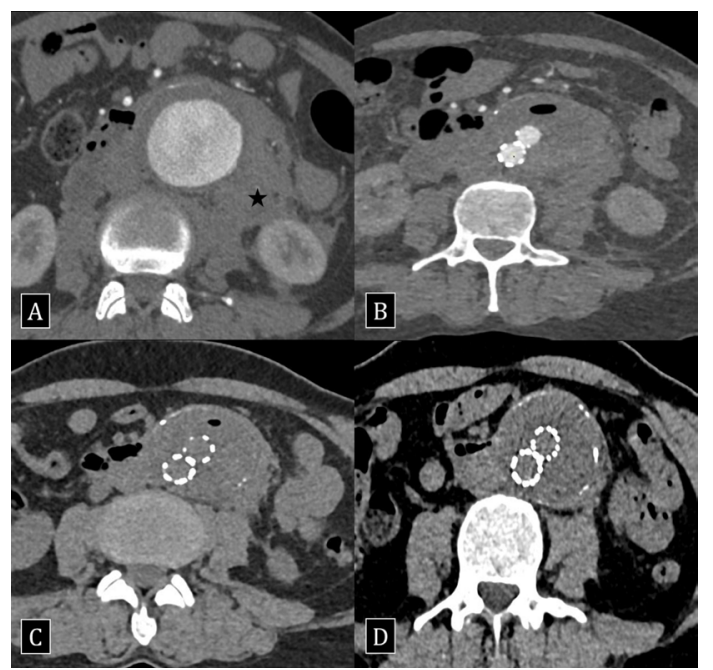

Figure $1 \mathrm{CT}$ axial image showing (A) abdominal aortic aneurysm with contained rupture (marked by a star). Day 5 postprocedure shows a patent stent-graft with a perigraft air focus (B), reduction of air focus at day 19 (C) and complete resolution at day 30 postprocedure CT (D).

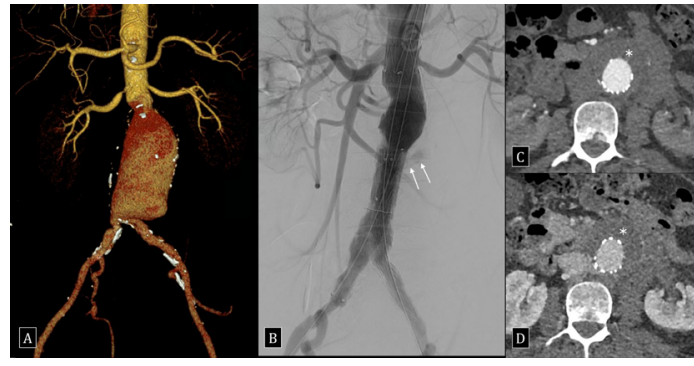

Figure 2 CT VRT image (A) showing abdominal aortic aneurysm extending up to the bifurcation and right renal artery stenosis (arrowhead). Digital subtraction angiography image (B) showing good proximal and distal approximation of stent-graft with an endoleak near the carina (arrows). Day 5 arterial (C) and venous (D) phase images shows patent stent-graft without pooling of contrast in the excluded aneurysmal sac (marked by an asterisk).

an endoleak due to the porosity of the stent-graft (type IV endoleak) as opposed to the manufacturing defects (type III endoleak).

A follow-up CT 5 days postprocedure did not show any contrast extravasation confirming the diagnosis of type IV endoleak (figure 2C,D). However, there was an air pocket seen in the thrombosed portion of the aneurysmal sac (figure 1B) without any peripheral enhancement or tissue infiltration to suggest secondary infection. The patient was afebrile without raised inflammatory markers or positive blood culture. The size of the air pocket was reduced at 19 days (figure 1C), and it completely disappeared at 30 days postprocedure (figure 1D). An interval reduction of the periaortic haematoma was also evident in serial CT scans (figure 1).

The endograft infection is one of the most dreaded complications post-EVAR with a significant in-hospital mortality rate $(19 \%-32 \%) .{ }^{1}$ The diagnosis is based on the clinical presentation, imaging findings, and lab parameters. Patients usually have constitutional findings like fever, pain, increased leucocyte and $\mathrm{C}$ reactive protein levels as well as positive blood culture. They can also present with fatigue, weight loss and bleeding per rectum (with aorto-enteric fistula). However, a minority of patients can be asymptomatic. The CT findings include periaortic tissue infiltration and enlarged lymph nodes as well as perigraft air. Adjacent bowel wall thickening or extravasation of contrast into the bowel lumen can also be noted in an aorto-enteric fistula. ${ }^{2}$ However, the mere presence of perigraft air is not indicative of the endograft infection without 


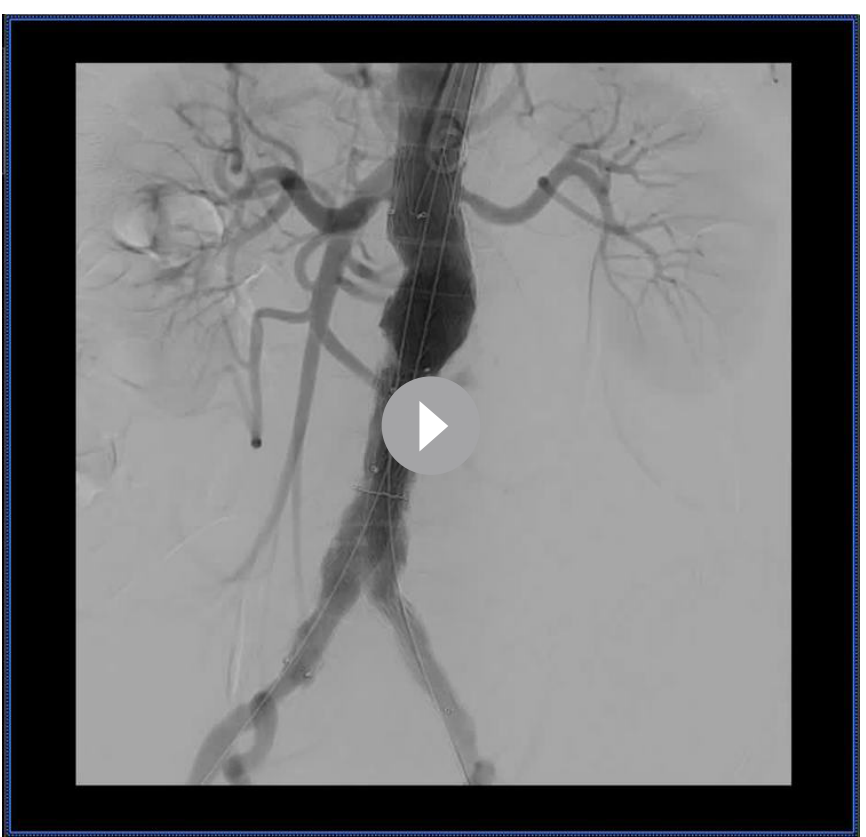

Video 1 Check angiogram postprocedure shows extravasation of contrast near the carina of the stent-graft (type IV endoleak).

the additional radiological, clinical or biochemical findings. The perigraft air in isolation can be seen up to 30 days post-EVAR, which may be due to the delivery of residual air bubbles in the outer sheath of the stent-graft during stent-graft deployment. ${ }^{34}$ In addition, fever, leucocytosis and perigraft air in the postoperative period can be related to postimplantation syndrome (PIS) and do not necessarily imply the endograft or systemic infection. It is postulated to be secondary to local inflammatory reaction and found to be more common with polyester graft material. PIS is usually managed conservatively, but it occasionally results in hepatic failure or adverse cardiovascular events. ${ }^{5}$ As a result, the patients with symptomatic or asymptomatic perigraft air should be monitored carefully to exclude the possibility of graft infection.

Type III endoleak is due to the separation of the stent-graft components or a defect in the fabric of the stent-graft. It can occur early due to component defect of the stent-graft or late due to material fatigue secondary to constant pulsatile forces of the blood column and eventual changes in the morphology of aneurysmal sac. ${ }^{6}$ There is usually a high-pressure leak through the defect in fabric into the aneurysmal sac. It can be seen on the Doppler examination as a high-velocity jet extending into the aneurysmal sac or on an angiogram as the continuous column of contrast extravasation as well as opacification and pooling of contrast into the aneurysmal sac. It often results in a measurable increase in the aneurysmal sac diameter and eventual rupture due to high pressure, if left untreated. ${ }^{7}$ Type IV endoleak, on the other hand, is due to the fabric-related porosity of the stent-graft and is rarely described in newer-generation devices due to high-density, multifilament polyester graft material. ${ }^{9}$ It is seen in the immediate postdeployment angiogram as a blush of contrast, usually without a discernible point of leakage. It occurs when the patient is anticoagulated and resolves spontaneously with normalisation of the coagulation profile. It is important to differentiate type IV from type III endoleak as the latter requires immediate sealing of the defect with an additional stent-graft or open repair, whereas the former is self-limiting. ${ }^{10}$

Thus, type IV endoleak and perigraft air are routine findings post-EVAR and should not be confused with disastrous type III endoleak and perigraft infection, respectively.

\section{Learning points}

- Perigraft air in isolation in the post-endovascular repair (EVAR) period is a routine finding and can be seen up to 1 month postprocedure. It should be differentiated from the perigraft infection based on additional radiographic, clinical and biochemical features.

- Fever, leucocytosis and perigraft air can be related to the postimplantation syndrome. It occurs secondary to local inflammatory reactions and is managed conservatively under careful monitoring.

- Type IV endoleak due to porosity in the fabric material is rarely seen in modern endoprosthesis used for EVAR. It is usually self-limiting and disappears postnormalisation of the coagulation profile of the patient. However, it should be differentiated from the disastrous type III endoleak due to a defect in the fabric, which needs to be managed immediately with an additional stent-graft or with open surgical repair.

Contributors AAD and DN-data collection and manuscript preparation. ASMdata analysis and manuscript editing. SK-manuscript proofreading and validation.

Funding The authors have not declared a specific grant for this research from any funding agency in the public, commercial or not-for-profit sectors.

Competing interests None declared.

Patient consent for publication Obtained.

Provenance and peer review Not commissioned; externally peer reviewed.

ORCID iD

Amit Ajit Deshpande http://orcid.org/0000-0001-7871-5688

\section{REFERENCES}

1 Argyriou C, Georgiadis GS, Lazarides MK, et al. Endograft infection after endovascular abdominal aortic aneurysm repair: a systematic review and meta-analysis. J Endovasc Ther 2017;24:688-97.

2 Setacci C, Chisci E, Setacci F, et al. How to diagnose and manage infected Endografts after endovascular aneurysm repair. Aorta 2014;2:255-64

3 Saleptsis V, Spanos K, Tsilimparis N, et al. The presence of gas in aneurysm sac during early postoperative period is associated to the type of endograft and perfused lumen's size. Ann Vasc Surg 2018:50:173-8.

4 Velázquez OC, Carpenter JP, Baum RA, et al. Perigraft air, fever, and leukocytosis after endovascular repair of abdominal aortic aneurysms. Am J Surg 1999;178:185-9.

5 Ito E, Toya N, Fukushima S, et al. Polyester grafts are a risk factor for postimplantation syndrome after abdominal endovascular aneurysm repair: retrospective analysis

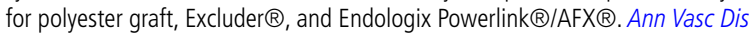
2018:11:520-4.

6 White GH, May J, Waugh RC, et al. Type III and type IV endoleak: toward a complete definition of blood flow in the sac after endoluminal AAA repair. J Endovasc 1998:5:305-9.

7 Bashir MR, Ferral H, Jacobs C, et al. Endoleaks after endovascular abdominal aortic aneurysm repair: management strategies according to CT findings. AJR Am J Roentgenol 2009;192:W178-86

8 Maleux G, Poorteman L, Laenen A, et al. Incidence, etiology, and management of type III endoleak after endovascular aortic repair. J Vasc Surg 2017;66:1056-64.

9 Bley T, Roos J. Pre- and Post-aortic Endovascular Interventions: What a Radiologist Needs to Know. In: Hodler J, Kubik-Huch RA, von Schulthess GK, eds. Diseases of the chest, breast, heart and vessels 2019-2022: diagnostic and interventional imaging [Internet]. Cham (CH): Springer, 2019.

10 Stavropoulos SW, Charagundla SR. Imaging techniques for detection and management of endoleaks after endovascular aortic aneurysm repair. Radiology 2007;243:641-55 
Copyright 2021 BMJ Publishing Group. All rights reserved. For permission to reuse any of this content visit https://www.bmj.com/company/products-services/rights-and-licensing/permissions/

BMJ Case Report Fellows may re-use this article for personal use and teaching without any further permission.

Become a Fellow of BMJ Case Reports today and you can:

- Submit as many cases as you like

- Enjoy fast sympathetic peer review and rapid publication of accepted articles

Access all the published articles

Re-use any of the published material for personal use and teaching without further permission

Customer Service

If you have any further queries about your subscription, please contact our customer services team on +44 (0) 2071111105 or via email at support@bmj.com.

Visit casereports.bmj.com for more articles like this and to become a Fellow 